\title{
Çevresel stres faktörlerinin sperm hücreleri üzerine etkisi
}

\section{The impact of environmental stress factors on sperm}

\author{
Eyyüp Sabri Pelit', Bülent Katıํำ Yiğit Akın², Ercan Yeni
}

\section{öz}

Sperm hücreleri morfolojik, fonksiyonel ve metabolik açıdan vücuttaki diğer hücrelere göre oldukça farkllılk gösterir. Bu nedenle, sperm hücrelerinin stres faktörlerine tepkisi somatik hücrelerden farklı olmaktadır. Defektif sperm sayısındaki artış genetik ve çevresel faktörlere bağlanabilir. Endüstriyel ve teknolojik sanayinin gelişmesine paralel olarak, artan çevresel toksinler, elektromanyetik radyasyon ve ksenobiyotiklerin sperm hücreleri üzerine negatif etkisi de ön plana çımaktadır. Toksinlerin, kimyasalların, tarım ilaçlarının, metal iyonlarının ve radyasyonun, sperm konsantrasyonu, hareketliliği, morfolojisi ve nükleer yapısı üzerine kötü etkileri literatürde kanıtlanmıştır. Semen parametreleri ile doğurganlığ karşılaştıran çalışmalarda, kalıcı çevresel kirleticilerin üremeyi etkileyen faktörlerden biri olduğu gösterilmiştir. Atık sularda aktif farmakolojik ajanların olmasının sperm Deoksiribonükleik asit (DNA) fragmantasyonunu arttırdığı ve sperm hücre hasarı yapabildiği, kanıtlanmış diğer bir faktördür. Tüm bunlar göz önüne alındığında, birçok çevresel ajanın sperm hücrelerinde defektler meydana getirerek erkek üreme potansiyelini düşürdüğü görülmektedir. Bu derlemede, sık maruz kalınan ve teknolojik gelişmeye bağlı olarak ortaya çıkan yeni çevresel faktörlerin spermatogenez üzerine etkilerinin gösterilmesi amaçlanmaktadır.

Anahtar Kelimeler: çevre kirliliği, erkek üreme sağlığı, sperm DNA

\section{ÇEVRESEL AJANLARIN ETKISi}

Sigara, radyasyon, ağır metal iyonları, alüminyum, flor, böcek ilaçları, alfatoksin ve organik çözücülerin sperm üzerine zararlı etkileri bilinmektedir. ${ }^{[1,2]}$ Bu çevresel faktörlerin, spermin özellikle fertilizasyon yeteneğini etkilediği düşünülmektedir. ${ }^{[3,4]}$ Overstreet ve ark. sperm hücrelerinin, çevresel ve mesleki maruz kaldıklarında somatik hücrelere göre daha hassas olduğunu göstermişlerdir. ${ }^{[5]}$ Ksenotok-

${ }^{7}$ Harran Üniversitesi Tıp Fakültesi, Üroloji Anabilim Dalı, Şanlıurfa

2izmir Katip Çelebi Üniversitesi Tıp Fakültesi, Üroloji Anabilim Dalı, İzmir

Yazışma Adresi / Correspondence:

Doç. Dr. Yiğit Akın

İzmir Katip Çelebi Üniversitesi Tıp Fakültesi, Üroloji Anabilim Dalı,

Çiğli Kampüsü, Dekanlık. İzmir / Türkiye

Tel. $\quad+905065334999$

E-mail:yigitakin@yahoo.com

Gelis / Received: $\quad 23.03 .2017$

Kabul / Accepted: 27.03.2017

\section{ABSTRACT}

Sperm cells are morphologically, functionally and metabolically very different from other cells in the body. For this reason, the response of sperm cells to stress factors is different from somatic cells. The increase in the numbers of defective sperms can be attributed to genetic and environmental factors. Increasing environmental toxins, electromagnetic radiation and xenobiotics have a negative effect on the sperm cells, parallel to the development of industrial and technological industries. The negative effects of toxins, chemicals, pesticides, metal ions and radiation on sperm concentration, motility, morphology and nuclear structure have been proven in the literature. In studies comparing fertility with semen parameters, it has been shown that persistent environmental pollutants are one of the factors affecting reproductivity. The presence of active pharmacological agents in the waste water is another proven factor that Deoxyribonucleic acid (DNA) fragmentation and sperm cell damage can be increased. Considering all these, it seems that many environmental agents can reduce male reproductive potential by producing defective sperm cells. In this compilation, it is aimed to show the effects of new environmental factors on spermatogenesis which we are frequently exposed and arise due to technological development.

Keywords: environmental pollution, male reproduction, sperm DNA

sinlerin somatik ve sperm hücre DNA'sına olan etkileri karşılaştırıldığında, spermatozoaların toksinlere karşı daha savunmasız olduğu gösterilmiş olup, bunun nedenin ise matür sperm hücrelerinin DNA hasarını tamir edebilecek enzimatik tamir mekanizmasının olmaması olarak gösterilmiştir. ${ }^{[6]}$ Oluşan DNA hasarları, sperm hücrelerinin çevresel stres faktörlerine karşı daha hassas olmasına yol açmaktadır. ${ }^{[7]} \mathrm{Bu}$ çalışmaların tamamı bize, sperm hücrelerinin çevresel toksinlere somatik hücrelerden daha hassas olduğunu göstermiştir.

Çevresel faktörlerin sperm hücreleri üzerindeki negatif etkisinin nasıl bir mekanizma ile olduğu halen tam olarak açıklanamamıştır. Her bir faktör ayrı mekanizmalar ile sperm hasarına neden olmaktadır. Radyasyon, sıcaklık, ilaçlar, alkilleyici kemoteropatik ilaçlar, böcek ilaçları ve aynı zamanda yaşam biçimi, alışkanlıklar ve bağımlılıklar gibi dış faktörler, sperm nükleer bütünlüğünü bozarak 


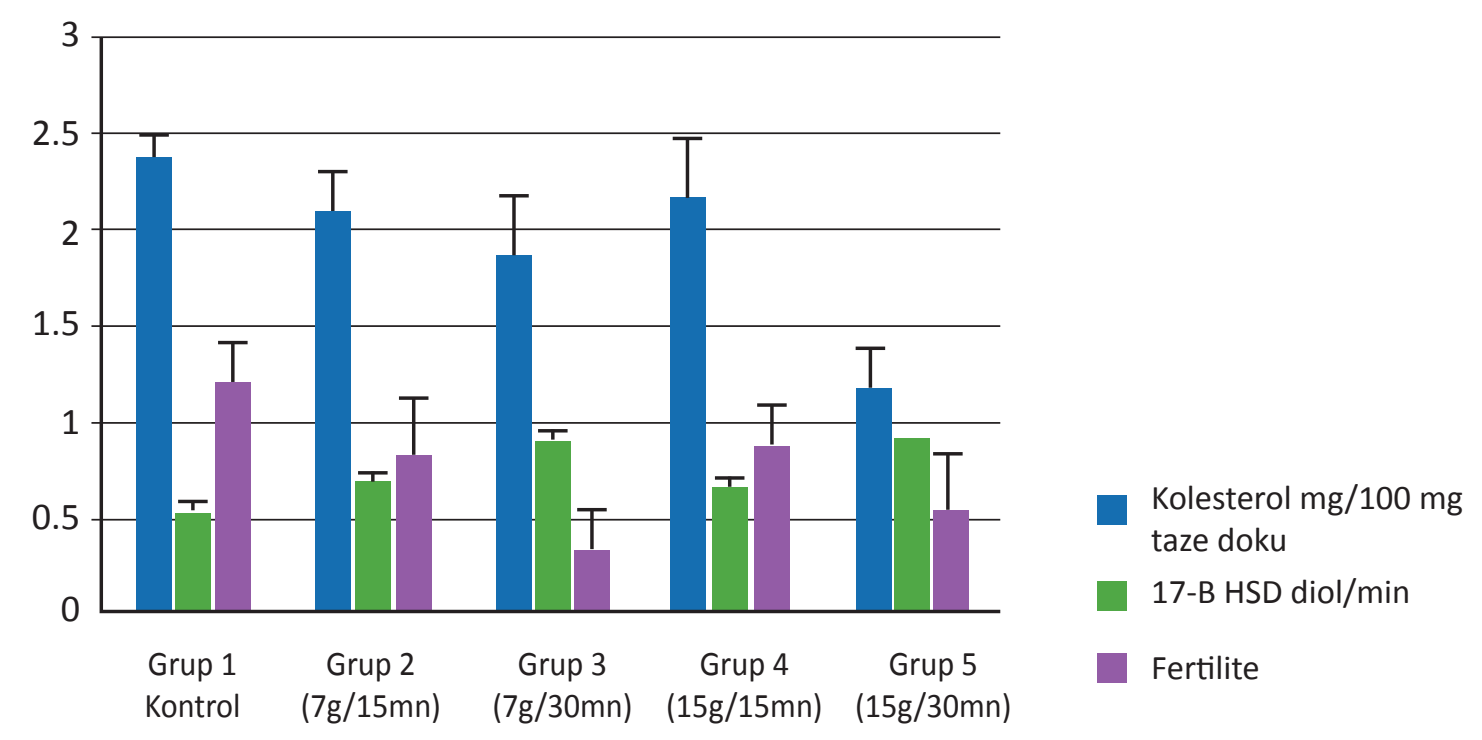

Resim 1. Radyasyon maruziyeti olan hayvanlarda ve kontrol grubunda testis $17 ß, 3 ß$ hidroksisterois dehidrogenaz ve testosteron seviyeleri.

fertiliteyi etkilemektedir. ${ }^{\left[{ }^{[8]}\right.}$ Aitken ve ark. çalışmalarında, DNA hasarının hem testiküler hem de post-testiküler alanda gerçekleşen kompleks bir mekanizma olduğunu göstermişlerdir. ${ }^{[9]}$ Delbes ve ark. bu hasar mekanizmasının tam olarak açıklanamadığını, genetik altyapı, yaşam biçimi ve çeşitli toksinlerin etkisine bağlı olarak geliştiğini savunmuşlardır. ${ }^{[10]}$

Hipertermi ve elektromanyetik radyasyon, sperm parametrelerini olumsuz yönde etkileyen faktörlerden ikisidir. Kaliteli spermatogenez, vücut sıcaklığından $2-4^{\circ} \mathrm{C}$ daha düşük bir sıcaklık gerektirmektedir. Kontrol grubu ile karşılaştırıldığında, obezlerde ve varikoseli olan hastalarda skrotal ısının daha fazla, total sperm konsantrasyonunun daha az ve follikül stimülan hormon (FSH) seviyesinin daha fazla olduğu görülmüştür. Sauna, sıcak su torbaları gibi dış ortam sıcaklık artışının da spermatogenezi bozduğu düşünülmektedir. ${ }^{[11-12]}$ Levine ve ark. semen parametrelerinin yaz aylarında kötüleştiğini göstermiştir. ${ }^{[13]}$ Dış ortamda çalışan işçiler ile kontrol grubu karşılaştırıldığında, bu veriler doğrulanmaktadır. ${ }^{[14]}$

Teknolojik gelişmelere bağlı olarak; mobil telefonlar, kablosuz internet servisleri ve dizüstü bilgisayarlar, insanların daha fazla elektromanyetik frekanslara maruz kalmasına neden olmaktadır. İyonize radyasyon, ultraviyole ve mikrodalga radyasyon, sperm hücrelerinin bilinen biyolojik düşmanlarıdır. Yapılan çalışmalarda, kızılötesi radyasyonun bile erkek üreme fonksiyonunu bozduğu görülmüştür. Yapılan bir hayvan çalışmasında, kısa süreli kızılötesi radyasyona $(900 \mathrm{~nm})$ maruz kalan hayvanların, steroid sentez basamaklarının etkilendiği, testosteron seviyesinin düştüğü ve sonuç olarak fertilitenin de düştüğü gösterilmiştir (Şekil 1). ${ }^{[15]}$ Cep telefonları $400 \mathrm{MHz}$ ile 2000 $\mathrm{MHz}$ arasında çalışır ve açığa çıkardıkları radyofrekans radyasyon, sperm sayısını azaltmaya yetmektedir. ${ }^{[16]} \mathrm{Ku}-$ mar ve ark. $10 \mathrm{GHz}$ elektromanyetik radyasyon maruziyeti sonrası, apoptotik parçalar, mikronükleuslar ve DNA sarmal kırıkları meydana geldiğini göstermişlerdir. ${ }^{[17]} \mathrm{Mo}-$ bil elektromanyetik sinyal önleyici cihazların da sperm motilitesini inhibe ettiği gösterilmiştir. Vihnera ve ark. elektromanyetik frekansın reaktif oksijen radikalleri oluşturarak sperm sayısını ve motilitesini azalttığını göstermişlerdir. ${ }^{[18]}$ Bahsedilen çalışmaların aksine, Fejio ve ark.'nın Brezilya erkeklerinde yaptıkları çalışma, mobil telefonlardan kaynaklanan radyofrekans elektromanyetik dalgaların sperm parametrelerini etkilemediğini desteklemektedir. ${ }^{[19]}$ Ülkemizden ratlar ile yapılan bir çalışmada denekler, 20 saat radyo frekansa maruz kalanlar, 8 saat maruz kalanlar ve kontrol grubu olarak 3 gruba ayrılmış, testiküler incelemede en fazla hasarın en uzun süre radyofrekansa maruz kalan grupta olduğu, maruziyet süresi artıkça testiküler hasarın arttığı gösterilmiştir. ${ }^{[20]}$ Mobil telefon kullanımı ve semen kalitesi arasındaki ilişkiyi değerlendiren güncel dört meta-analizin ikisinde, sperm konsantrasyonunda ileri derecede azalma görülmüş ve bir meta-analizde sonuçlar çelişkili bulunmuş; diğer meta-analizde ise ratlarda sperm konsantrasyonu düşerken insanlarda herhangi bir düşüş görülmemiştir. ${ }^{[21]}$ Özet olarak; radyofrekans radyasyonun üreme sistemi üzerine toksisitesi hakkında çelişkili raporlar mevcuttur. ${ }^{[22]}$ Tüm bu karmaşık ve birbirine kar- 
şıt literatür verilerinden, teknolojik gelişmeler ile üretilen yukarıda bahsi geçen cihazların sperm matürasyonuna kötü etkileri daha ağır basmaktadır.

Alkolün, spermatogenezin birçok basamağında etkili olduğu gösterilmiştir. Hayvan çalışmalarında, alkolün hipotalamo-hipofizer-testis aksını etkilediği kanıtlanmıştır; Sertoli ve Leyding hücrelerine direkt olarak toksik etkisi mevcuttur. Böylelikle, alkol spermatogenezi hem pituiter hem de testiküler seviyede etkilemektedir. ${ }^{[23]}$ Ratlarda yapılan diğer bir çalışmaya göre ise, alkol kullanımı sperm parametrelerinde kontrol grubuna göre anlamlı değişiklikler meydana getirmektedir ve sperm kromatin/DNA hasar oranını arttırmaktadır. ${ }^{[24]}$ Altı yüz seksen beş alkolik hastada yapılan çalışmada, alkolün spermin motilitesini azalttığı gösterilmiştir. Neden olarak, aşırı alkol tüketimine bağlı olarak gelişen prostatit tablosuna sekonder olduğu düşünülmüştür. ${ }^{[25]}$ Ayrıca, 3000 hastada yapılan diğer bir çalışmada, alkolik hastalar alkol kullanmayan hastalar ile karşılaştırılmıştır. Sonuç olarak, alkolik hastaların seminal sıvilarında lökosit miktarının artmış olduğu ve bu hastaların inflamasyona daha yatkın olduğu, böylece sperm parametrelerinde bozulma meydana gelebileceği düşünülmüşsür. ${ }^{[26]}$

Sigarının spermotagenez üzerine ve canlı doğum oranları üzerine negatif etkisi olduğu bilinmektedir. Sigara içenler ile içmeyenlerin karşılaştırıldığı beş ayrı çalışmanın meta-analizine bakıldığında, sigara içen grubun sperm konsantrasyonunun diğer gruba göre ileri derecede azalmış olduğu gösterilmiştir. ${ }^{[27]}$ Sigaranın içeriğindeki polisiklik aromatik hidrokarbonların ve diğer kimyasallar, hızlı bölünen hücrelerde mutasyon, apoptoz ve hücre ölümüne neden olmakta, böylelikle hücre bölünmesini yavaşlatıp spermatogenezi azaltmaktadır. ${ }^{[23]}$ Sigara aynı zamanda, kan karbonmonoksit seviyesi arttırmakta ve testislerde kısmi hipoksi meydana getirmektedir. ${ }^{[28]}$ Sigaranın eskiden beri bilinen, serum toplam testosteron seviyesini arttırdığı gösteren yazılara rağmen, son yıllardan yapılan araştırmalar yukarıdaki sonuçları göstermiştir. ${ }^{[29]}$ Sigara, günümüzde sperm hücre hasarına en sık neden olan çevresel kirleticiler arasındadır.

Esrarın spermatogenez üzerine etkisini araştıran yeterince çalışma, tasarım güçlüğü nedeni ile yoktur. Yapılan sınırlı sayıdaki çalışmalarda, esrarın akut olarak lüteinizan hormon (LH) seviyesini düşürdüğü gösterilmiştir. Fakat, kronik kullanımda düşük seviyede bazal bir LH seviyesi oluşturur ve gonadotropin salgılatıcı hormona düşük yanıt verilmesine neden olur. Kronik yoğun esrar kullanımı, doz bağımlı şekilde testosteronu düşürür ve bu kişilerin $\% 35$ 'inde oligospermi görülmektedir. ${ }^{[30-31]}$

Tüm dünyada profesyonel sporcular, özellikle vücut geliştiriciler, kas doku oranını geliştirmek ve performanslarını arttırmak için anabolik steroidleri kullanmaktadırlar. Anabolik steroidler, testosteronu taklit ederek hipogonadotropik hipogonadizme neden olur. Kısacası, yükselmiş serum androjen seviyesi negatif feed-back ile pituiter LH, FSH üretimini baskılar. Düşük FSH ve LH seviyesi testiküler testosteron üretimini azaltır; dolayısıyla intra-testiküler testosteron seviyesi düşer. Sonuç olarak, spermatogenez bozulur. ${ }^{[32]}$

Narkotik ilaç bağımlılığının sperm hücreleri üzerine etkisi olduğu gösterilmiştir. Opiat bağımlı 142 erkek ile sağlıklı kontrol grubu karşılaştırıldığında, bağımlılarda sperm sayısının ileri derecede düşük olduğu gözlemlendi. Opiat kullananlarda ve kontrol grubunda ortalama sperm konsantrasyonu, sırası ile $22,2 \pm 4,4 \mathrm{mil} / \mathrm{mL}$ ve $66,3 \pm 8,3 \mathrm{mil} /$ $\mathrm{mL}$ idi $(\mathrm{p}=0,002)$. Opiat kullananlar kontrollerle karşılaştırıldığında, fragmante DNA miktarında belirgin bir artış

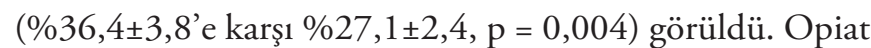
kullananlar sağlıklı bireylerle karşılaştırıldığında, katalaz benzeri ve süperoksit dismutaz benzeri (SOD) aktivite düzeylerinde belirgin olarak azalma gözlendi. Sonuç olarak; opiat kullanımının semen kalitesini negatif yönde etkilediği kanıtlanmıştır ve açıklanamayan erkek faktör infertilitede akılda tutulmalıdır. ${ }^{[33]}$

\section{SONUÇ}

Teknolojik gelişmelere bağlı olarak, testiküler sağlığı tehdit eden yeni çevresel etmenler ortaya çıkmaktadır. Yaşam stili, çevresel ve mesleki maruziyetin spermatogenez üzerine etkileri mevcuttur. Her bir faktörü ayrı ayrı belirlemek, sadece hayvan modellerinde mümkün olmaktadır ve klinik çalışmalarda halen tartışmalı sonuçlar yayımlanmaktadır.

Her bir ayrı ajana kronik maruziyetin etkisini anlamak için geniş tabanlı prospektif randomize kontrollü çalışmalara ihtiyaç vardır, ancak bu çalışmaları etik açıdan yürütmek mümkün değildir. Bunu yenmek için toplum tabanlı çalışmalar yardımcı olabilir kanaatindeyiz.

\section{KAYNAKLAR}

1. Aitken RJ. Human spermatozoa: revelations on the road to conception. F1000Prime 2013;5:39. doi: 10.12703/P5-39

2. Buck Louis GM, Sundaram R, Schisterman EF, Sweeney AM, Lynch CD, et al. Persistent environmental pollutants and couple fecundity: the LIFE study. Environ Health Perspect 2013;121:2316. doi: 10.1289/ehp.1205301

3. Rocco L, Peluso C, Cesaroni F, Morra N, Cesaroni D, Stingo V. Genomic Damage in Human Sperm Cells Exposed In Vitro to Environmental Pollutants. J Environment Analytic Toxicol 2012;2:117. doi: 10.4172/2161-0525.1000117

4. Klassen CD, Amdur MO, Doull L. Casarett and Doull's Toxicology: the basic science of poisons, 3rd ed. New York: Macmillan Publishing Co.; 1986. 
5. Overstreet JW, Samuels SJ, Day P, Hendrickx AG, Prahalada S, et al. Early indicators of male reproductive toxicity. Risk Anal 1988;8:21-6.

6. Anderson D, Yu TW, Browne MA. The use of the same image analysis system to detect genetic damage in human lymphocytes treated with doxorubicinin the Comet and fluorescence in situ hybridization (FISH) assay. Mutat Res 1997;390:69-77.

7. Sakkas D, Alvarez JG. Sperm DNA fragmentation: mechanisms of origin, impact on reproductive outcome, and analysis. Fertil Steril 2010;93:1027-36. doi: 10.1016/j.fertnstert.2009.10.046

8. Delbès G, Hales BF, Robaire B. Toxicants and human sperm chromatin integrity. Mol Hum Reprod 2010;16:14-22. doi: 10.1093/molehr/gap087

9. Aitken RJ, De Iuliis GN, Finnie JM, Hedges A, McLachlan RI. Analysis of the relationships between oxidative stress, DNA damage and sperm vitality in a patient population: development of diagnostic criteria. Hum Reprod 2010;25:2415-26. doi: 10.1093/ humrep/deq214

10. Delbès G, Hales BF, Robaire B. Toxicants and human sperm chromatin integrity. Mol Hum Reprod 2010;16:14-22. doi: 10.1093/molehr/gap087

11. Garolla A, Torino M, Miola P, Caretta N, Pizzol D, Menegazzo M, Bertoldo A, Foresta C. Twenty-four-hour monitoring of scrotal temperature in obese men and men with a varicocele as a mirror of spermatogenic function. Hum Reprod 2015;30:1006-13. doi: 10.1093/humrep/dev057

12. Sheynkin Y, Jung M, Yoo P, Schulsinger D, Komaroff E. Increase in scrotal temperature in laptop computer users. Hum Reprod 2005;20:452-5. doi: 10.1093/humrep/deh616

13. Levine RJ, Brown MH, Bell M, Shue F, Greenberg GN, et al. Airconditioned environments do not prevent deterioration of human semen quality during the summer. Fertil Steril 1992;57:1075-83.

14. Levine RJ. Seasonal variation of semen quality and fertility. Scand J Work Environ Health 1999;25 Suppl 1:34-7.

15. Highland HN, Bhatt SN, George LB. Biochemical and Histoarchitectural alteration in mouse testis on exposure to infrared radiation. Toxicol Int 2003;10:23-9.

16. Agarwal A, Makker K, Sharma R. Clinical relevance of oxidative stress in male factor infertility: an update. Am J Reprod Immunol 2008;59:2-11. doi: 10.1111/j.1600-0897.2007.00559.x

17. Kumar S, Behari J, Sisodia R. influence of electromagnetic fields on reproductive system of male rats. Int J Radiat Biol 2013 89:14754. doi: 10.3109/09553002.2013.741282

18. La Vignera S, Condorelli RA, Vicari E, D'Agata R, Calogero AE. Effects of the exposure to mobile phones on male reproduction: a review of the literature. J Androl 2012;33:350-6. doi: 10.2164/ jandrol.111.014373

19. Adams JA, Galloway TS, Mondal D, Esteves SC, Mathews F. Effect of mobile telephones on sperm quality: a systematic review and meta-analysis. Environ Int 2014;70:106-12. doi: 10.1016/j. envint.2014.04.015
20. Karaman MI, Gökçe AM, Koca O, Karaman B, Öztürk MI, Yurdakul N, et al. The effects of electromagnetic waves emitted by the cell phones on the testicular tissue. Arch Ital Urol Androl 2014;86:274-7. doi: 10.4081/aiua.2014.4.274

21. La Vignera S, Condorelli RA, Vicari E, D’Agata R, Calogero AE. Effects of the exposure to mobile phones on male reproduction: a review of the literature. J Androl 2012;33:350-6. doi: 10.2164/ jandrol.111.014373

22. Merhi ZO. Challenging cell phone impact on reproduction: a review. J Assist Reprod Genet 2012;29:293-7. doi: 10.1007/ s10815-012-9722-1

23. Emanuele MA, Emanuele NV. Alcohol's effects on male reproduction. Alcohol Health Res World 1998;22:195-201.

24. Pourentezari M, Talebi AR, Mangoli E, Anvari M, Rahimipour M. Additional deleterious effects of alcohol consumption on sperm parameters and DNA integrity in diabetic mice. Andrologia 2016;48:564-9. doi: 10.1111/and.12481

25. Molnár J, Papp G. Alcohol as a possible stimulant of mucous production in the semen. Andrologie 1973;5:105-6.

26. Martin-Boyce A, David G, Schwartz D. Genitourinary infection, smoking and alcohol in the male. Rev Epidemiol Sante Publique 1977;25:209-16.

27. Ramlau-Hansen CH, Thulstrup AM, Aggerholm AS, Jensen MS, Toft G, Bonde JP. Is smoking a risk factor for decreased semen quality? A cross-sectional analysis. Hum Reprod 2007;22:188-96. doi: 10.1093/humrep/del364

28. Koskinen LO, Collin O, Bergh A. Cigarette smoke and hypoxia induce acute changes in the testicular and cerebral microcirculation. Ups J Med Sci 2000;105:215-26.

29. Zhao J, Leung JY, Lin SL, Schooling CM. Cigarette smoking and testosterone in men and women: A systematic review and metaanalysis of observational studies. Prev Med 2016;85:1-10. doi: 10.1016/j.ypmed.2015.12.021

30. Cone EJ, Johnson RE, Moore JD, Roache JD. Acute effects of smoking marijuana on hormones, subjective effects and performance in male human subjects. Pharmacol Biochem Behav 1986;24:1749-54.

31. Vescovi PP, Pedrazzoni M, Michelini M, Maninetti L, Bernardelli F, Passeri M. Chronic effects of marihuana smoking on luteinizing hormone, follicle-stimulating hormone and prolactin levels in human males. Drug Alcohol Depend 1992;30:59-63.

32. De Souza GL, Hallak J. Anabolic steroids and male infertility: a comprehensive review. BJU Int 2011;108:1860-5. doi: 10.1111/j.1464-410X.2011.10131.x

33. Safarinejad MR, Asgari SA, Farshi A, Ghaedi G, Kolahi AA, Iravani S, Khoshdel AR. The effects of opiate consumption on serum reproductive hormone levels, sperm parameters, seminal plasma antioxidant capacity and sperm DNA integrity. Reprod Toxicol 2013;36:18-23. doi: 10.1016/j.reprotox.2012.11.010 